\title{
Scenario of Infection Prevention and Control Measures for Tuberculosis in Tuberculosis Inpatient and Outpatient Department in Tertiary Care Hospital
}

\author{
Yogita Mistry ${ }^{1,2}$, Sangita Rajdev33, Summaiya Mullan ${ }^{3}$ \\ ${ }^{1}$ TB-IRL Laboratory, Surat, India \\ ${ }^{2}$ Government Medical College, Surat, India \\ ${ }^{3}$ Department of Microbiology, Government Medical College, Surat, India \\ Email: dryogitamistry@gmail.com
}

How to cite this paper: Mistry, Y., Rajdev, S. and Mullan, S. (2016) Scenario of Infection Prevention and Control Measures for Tuberculosis in Tuberculosis Inpatient and Outpatient Department in Tertiary Care Hospital. Journal of Tuberculosis Research, 4, 147-154.

http://dx.doi.org/10.4236/jtr.2016.44018

Received: November 2, 2016

Accepted: November 20, 2016

Published: November 23, 2016

Copyright (๑) 2016 by authors and Scientific Research Publishing Inc. This work is licensed under the Creative Commons Attribution International License (CC BY 4.0).

http://creativecommons.org/licenses/by/4.0/

\section{c) (i) Open Access}

\begin{abstract}
Tuberculosis is one of the most important infectious diseases in our country. Also nosocomial infection by tuberculosis can occur, which can be prevented by implementing simple, effective and affordable tuberculosis infection control measures in health care facilities. To evaluate the effectiveness of infection control measures, such study was planned. Questionnaires were administered to all doctors, healthcare workers and servants working in outdoor and indoor department of tuberculosis at tertiary care hospital to assess the knowledge, attitudes and practices on prevention and control of Tuberculosis infection. A scoring system was devised to grade them. One-time audit was also done in outpatient and inpatient department. The analysis showed scoring of poor for doctors, good for nurses and poor forward aids. There is a need to develop strategies for training of health care workers on regular basis in order to reduce the incidence of nosocomial infections. Audit result shows a good level of environmental control measures. Better knowledge, attitude and practices are helpful for the prevention and control of tuberculosis. Also environmental control measures are helpful to prevent infection.
\end{abstract}

\section{Keywords}

Infection Prevention and Control Measures, Tuberculosis, Tuberculosis Departments

\section{Introduction}

Tuberculosis is an infectious disease which has high mortality and morbidity. The risk 
of TB transmission in health care workers from patients having Tuberculosis or from patients who are undiagnosed and visiting or admitting in the hospital is now well documented [1].

The World Health Organization (WHO) recommends four types of infection control measures in health facilities: managerial measures, administrative measures, proper ventilation and personal protective equipment. When these measures are properly implemented, then they have been found to minimize the transmission of tuberculosis in health facilities. WHO therefore recommends that all health facilities caring for tuberculosis patients or persons suspected of having tuberculosis should implement these measures. As assessment of such measures has not been done in tertiary care hospital, Surat, purpose of this study was to know implementation of tuberculosis infection prevention and control measures in tertiary care hospital, Surat [2] [3].

\section{Methodology}

Study was started after getting ethical approval only. It is a cross sectional study with audit tool once in outpatient and indoor patient department of tuberculosis and questionnaires. All health care workers, doctors and servant's working in tuberculosis inpatient and outpatient department were included in the study with sample size of 35 - 40. Questionnaires were made to know about knowledge, attitude and practices among all health care workers to cover different aspect of infection prevention and control measures, out of which many questions were from WHO guideline. It was made in English, Hindi and Local Gujarati language. Right question was scored as +1 and wrong question was scored as 0 . Over all questionnaires was analyzed using KAP scoring method. Scoring in range of 8 - 10 was graded as excellent, between 4 and 7 was graded as good and between 0 and 3 was graded as poor.

Different aspect of questionnaires:

\subsection{Personal Protection}

1) What is N-95 mask?

2) What you feel, is it helpful to use N-95 mask?

3) Have you been provided with N-95 mask?

4) What is nosocomial infection?

5) Do you believe that health care worker is at risk of acquiring a nosocomial infection?

6) Have you ever done your check up related to TB diagnosis?

7) Do you feel that there should be routine health check-up of HCW for diagnosis of TB?

\subsection{Biomedical Waste}

1) Is there someone in charge of TB infection control?

2) What should be done when specimen container is soiled on the outside?

3) What should be done when lab request form is soiled?

4) Which disinfectant should be used for spillage with TB infectious material? 
5) Which disinfectant is used for discarding of sputum sample?

6) Do you feel is it necessary to discard the infected samples in container with proper disinfectant?

\subsection{Universal Precaution}

1) Have you ever heard about universal precaution?

2) Universal precaution is compulsory/protective?

3) Universal precaution should be observed at all patients/all time in all patients/for HIV patients?

\subsection{Hand Washing}

1) Will hand washing prevent spread of infection?

2) Do you change gloves in between two patients?

3) What is the ideal time for routine hand washing?

4) What do you feel hand washing should be performed in between two patients?

5) Are you trained on TB infection control practices?

\subsection{Patients Separation and Education}

1) Is tuberculosis infected patients can transmit the infection to their family and to their contact persons?

2) What is cough hygiene?

3) Are patients and their families educated on TB infection control practices?

4) Are patients educated about how to take sputum sample?

5) Is there any facility to separate chest symptomatic patients from other patients in the waiting are of outpatient department?

6) Is there any facility to separate infectious patients from other patients in ward?

7) Is there any facility to separate MDR patients from other patients in ward?

8) Is it cumbersome or helpful to separate chest symptomatic patients from other patients?

9) All respiratory symptomatic patients given surgical mask in OPD area?

10) Is there any facility for early diagnosis of suspected TB patient and receiving of results?

\section{Result}

In audit tool of outpatient department, it was observed that there was a well ventilated waiting area with sitting facilities. Also there was a facility to triage/separate the already diagnosed patients of tuberculosis from other patients, which helps in decreasing the spread of infection. Surgical mask was given to all diagnosed patients of tuberculosis and also it was used by all health care workers of that area. As an environment control measures, ceiling fans and cross ventilation system was there which helps in dispersing the pathogen from its source of generation. Cough etiquette was taught to all diagnosed patients of tuberculosis. 
Audit of inpatient department had shown that, it was a separate ward from other wards of hospitals and also a separate ward for MDR-tuberculosis patients to decrease the spread of infection to other ward patients. Ceiling fans and cross ventilation was there as an environmental control measure. All patients and health care workers were using surgical mask for personal protection.

Questionnaires were asked to 7 doctors, 15 para-medical staff and 8 servants who were working in tuberculosis inpatient and outpatient department. Because others were absent at the time of study. All 7 doctors were male, out of which 4 were working since 3 years and 3 were working since 9 years. Out of 15 healthcare workers (paramedical staff) 6 were working since 10 years and 7 were working since 4 years. Out of 8 servants 2 were newly joined since 4 months and 6 were working since 4 years. Analysis of questionnaires was done by using KAP score. Score 1 - 10 was graded as poor, 11 - 20 was graded as good and 21 - 30 was graded as excellent score.

Overall analysis of KAP score is mentioned in Figure 1. KAP score analysis of all doctors was excellent \& good. In Health care workers it was 37\% excellent and good and $26 \%$ poor. In servants it was also excellent, good and poor.

Personal protection related questionnaires analysis is shown in Figure 2. In all doctors KAP score was good for personal protection related questions, but it was not excellent due to practice issue for personal protection. They all had well knowledge about

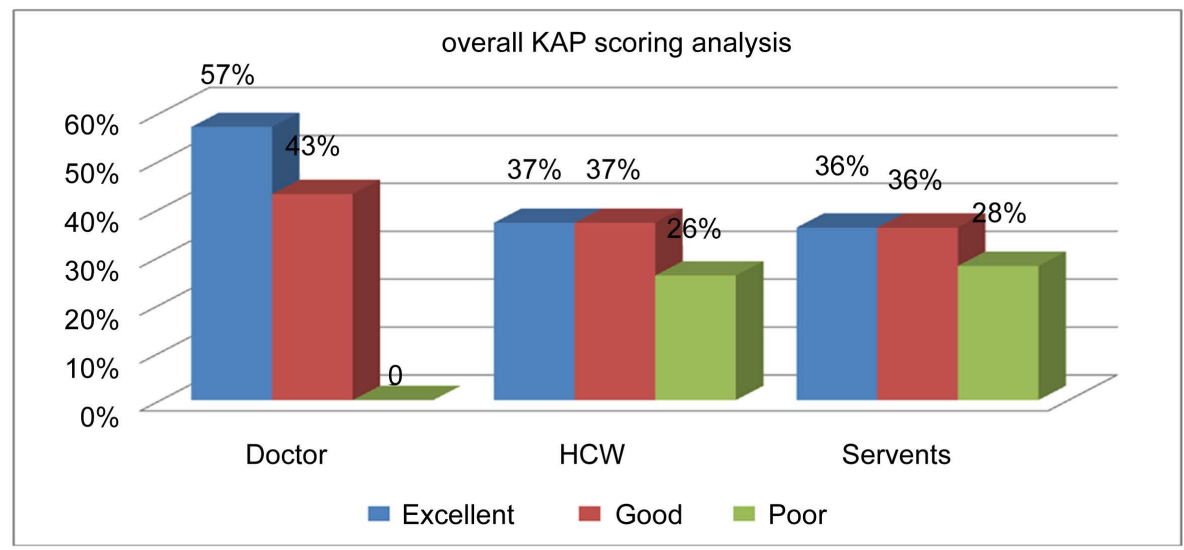

Figure 1. Overall KAP scoring analysis.

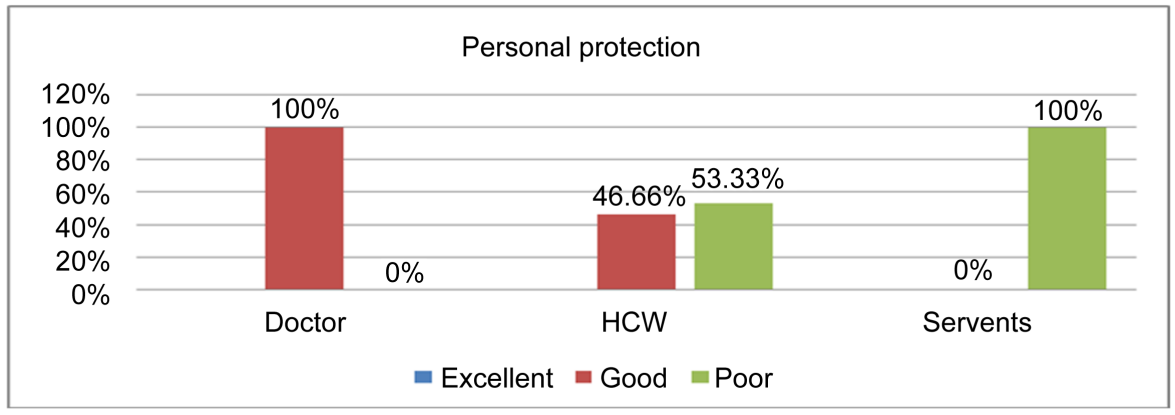

Figure 2. KAP analysis for questionnaires related to personal protection. 
N-95 masks, nosocomical infection, about their health check up for diagnosis of tuberculosis infection in them. They all had well attitude about personal protection. Only gap was in practices. They were not doing their routine heath checkup for TB infection diagnosis. In other health care workers groups KAP score was $46.66 \%$ good and $53.33 \%$ poor. As compared to doctors groups HCW groups were not aware about N-95 mask, about the importance of their health check up for tuberculosis diagnosis. In servants groups KAP score was poor. They did not have any good knowledge about their protection in relation to tuberculosis disease.

Figure 3 is showing KAP analysis related to biomedical waste related questions. In doctors group score was excellent. They have proper knowledge, attitude and practices for BMW. In HCW group score was 73.33\% excellent and 26.66\% good. Major gap was in practices related to soiled container and soiled requisition form discarding. Overall KAP score in servants was $71.42 \%$ excellent and $28.57 \%$ was poor. Major gap was in knowledge of disinfectant concentration and in practices for discarding soiled containers.

Figure 4 had shown analysis of hand washing questionnaires. $62.50 \%$ score was good and $37.50 \%$ was excellent in doctors group. They had good knowledge about importance of hand washing in prevention of TB spread, timing of hand washing and also have good attitude and practices of changing of gloves in between two patients. In HCW groups over all score was good (46.66\%). 20\% poor scoring in HCW was due to insufficient training of HCW. In servant groups $57.14 \%$ was good score, $28.54 \%$ excellent and $14.28 \%$ was poor. These were also due to insufficient training and also due to frequent change in staff.

Figure 5 shows analysis of KAP score for universal precaution question, which shows better knowledge, attitude and practices in doctors, but it was poor (33.33\%) in

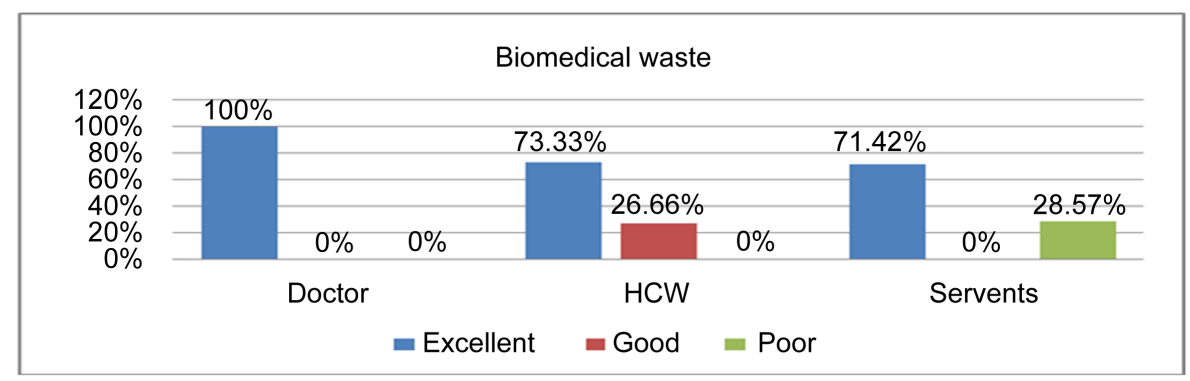

Figure 3. KAP analysis for questionnaires related to biomedical waste.

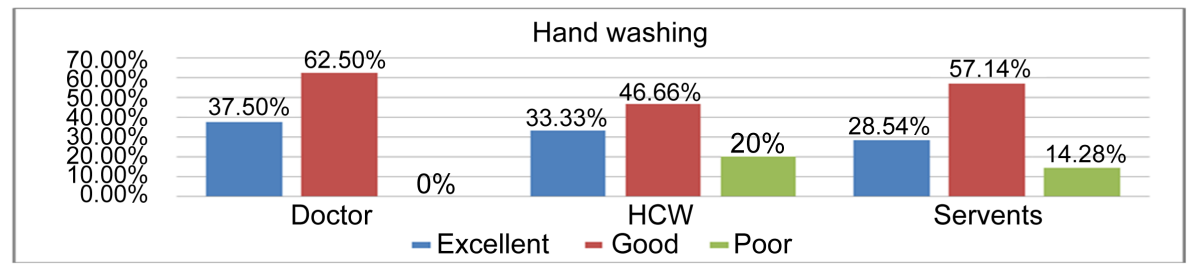

Figure 4. KAP analysis for questionnaires related to Hand washing. 


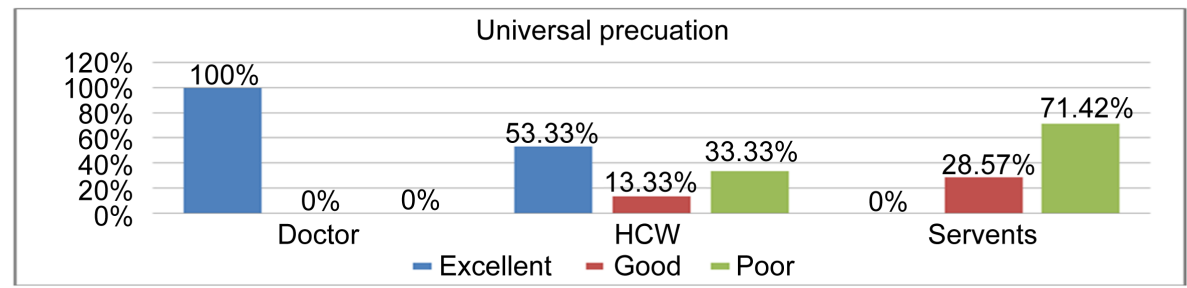

Figure 5. KAP analysis for questionnaires related to universal precautions.

HCW and servants (71.42). Major gap was in practices in cases of health care workers about knowledge it universal precaution should be taken at each and every patients and in knowledge and attitude in cases of servants as they were not knowing what is universal precaution.

In Figure 6 questionnaires for TB infected patients separation and education has been shown. These questionnaires were asked only to doctors and health care workers. KAP score was good in doctors and it was good to poor in health care workers. Major gap was in practices in both groups. They had better knowledge and attitude about cough hygiene, importance of separation of coughing patients and HIV patients from other patients, but they were not practicing it, which may be due to poor management in hospital for patients' separation.

\section{Discussion}

Finding in this study provide important information on current status of implementation of TBIC (TB infection control measures) in tertiary care institute, which shows that there is a need for implementation of recommended TBIC practices and training for staff.

In inpatient and outpatient department, infection prevention and control measures can still be improved by providing N-95 mask to all health care workers and also to all diagnosed patients. Instead of triaging only to diagnosed patients of tuberculosis, all suspected patients of tuberculosis like coughing patients, visually ill looking patients should also be triaged. There should also be a facility to give priority to all these patients in other areas of hospital where they are visiting and spending more time in waiting area like radiology department. In inpatients department, open case of pulmonary tuberculosis should be separated from non pulmonary patients and also from patients with HIV.

Natural ventilation has also limitation due to weather and comfort issue. So education in health care workers to maximize the cross ventilation by opening windows should be given, which is an easy, low cost intervention to reduce the airborne exposure from tuberculosis [4]. Several study also have shown that ultraviolet germicidal irradiation system can disinfect mycobacteria and other organisms, but its use should not be to replace the natural ventilation but as a complementary intervention [5] [6] [7].

In questionnaires of Knowledge, attitude and practices major gap was found in the personal protection part in all groups. All participants were not doing their routine 


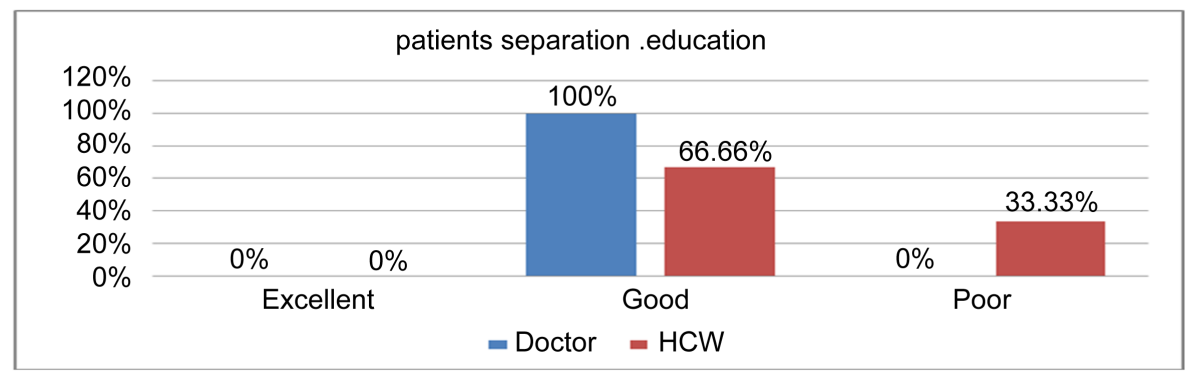

Figure 6. KAP analysis for questionnaires related to patient separation and education.

health check-up for diagnosis of TB infection. These may be due to lack of education and motivation. Also servant's groups having poor knowledge about universal precaution and personal protection. So frequent training should be taken to increase their knowledge, attitude and practices for better TB infection, prevention and control measures. This knowledge-practice discrepancy has been found in many other settings in both the resource-limited and resource rich countries [8] [9] and highlights the need for more than just educational initiatives to increase infection control practices.

\section{Limitations}

In this study administrative aspect has not been included which also plays major role in infection prevention \& control. Also assessment of incidence of latent tuberculosis in health care workers has not been done. Training of health care workers after such conclusion was not planned at the time of study. Assessment of existing infection control measures was done and we were unable to differentiate quality, comprehensive or consistency of implementation of all measures.

\section{Future Scope}

Training and retraining of health care workers at regular interval based on local policy of hospital should be done for better infection prevention \& control.

\section{Conflict of Interests}

The present study was funded from research funds of the authors. No pharmaceutical grants were used for this study.

\section{Ethical Clearance}

Approved by HREC committee of Government Medical College, Surat.

\section{References}

[1] (1999) Tuberculosis Infection Control in the Era of Expanding HIV Care and Treatment. Addendum to Who Guidelines for the Prevention of Tuberculosis in Health Care Facilities in Resource-Limited Settings.

[2] (2008) Guidelines for Infection Prevention and Control for TB Including MDR-TB and XDR-TB. 
[3] Mareli, M.C., Cari, S., Elizabeth du, T., Eline, R., Carl, J.L., Donald, A.E., et al. (2013) Tuberculosis in Healthcare Workers and Infection Control Measures at Primary Healthcare Facilities in South Africa. Published: October 2.

[4] (2009) WHO Policy on TB Infection Control in Health-Care Facilities, Congregate Settings and Households. World Health Organization.

[5] Escombe, A.R., Oeser, C.C., Gilman, R.H., Navincopa, M., Ticona, E., Pan, W., et al. (2007) Natural Ventilation for the Prevention of Airborne Contagion. PLoS Medicine, 4, e68. https://doi.org/10.1371/journal.pmed.0040068

[6] Memarzadeh, F., Olmsted, R.N. and Bartley, J.M. (2010) Applications of Ultraviolet Germicidal Irradiation Disinfection in Health Care Facilities: Effective Adjunct, But Not Stand-Alone Technology. American Journal of Infection Control, 38, S13-S24.

[7] Nardell, E.A., Bucher, S.J., Brickner, P.W., Wang, C., Vincent, R.L., Becan-McBride, K., et al. (2008) Safety of Upper-Room Ultraviolet Germicidal Air Disinfection for Room Occupants: Results from the Tuberculosis Ultraviolet Shelter Study. Public Health Reports, 123, 52-60.

[8] Sethi, A.K., et al. (2012) Infection Control Knowledge, Attitudes, and Practices among Healthcare Workers at Mulago Hospital, Kampala, Uganda. Infection Control and Hospital Epidemiology, 33, 917-923. https://doi.org/10.1086/667389

[9] Buregyeya, E., Nuwaha, F., Verver, S., Criel, B., Colebunders, R., Wanyenze, R., Kalyango, J.N., Katamba, A. and Mitchell, E.M.H. (2013) Implementation of Tuberculosis Infection Control in Health Facilities in Mukono and Wakiso Districts, Uganda. BMC Infectious Diseases, 13, 360 .

\section{Submit or recommend next manuscript to SCIRP and we will provide best service for you:}

Accepting pre-submission inquiries through Email, Facebook, LinkedIn, Twitter, etc.

A wide selection of journals (inclusive of 9 subjects, more than 200 journals)

Providing 24-hour high-quality service

User-friendly online submission system

Fair and swift peer-review system

Efficient typesetting and proofreading procedure

Display of the result of downloads and visits, as well as the number of cited articles

Maximum dissemination of your research work

Submit your manuscript at: http://papersubmission.scirp.org/

Or contact jtr@scirp.org 